\title{
Cerium Oxide Nanoparticles Protect Cardiac Progenitor Cells from Oxidative Stress
}

\author{
Francesca Pagliari, ${ }^{\dagger, \pm, \|}$ Corrado Mandoli, ${ }^{\S, \|}$ Giancarlo Forte, ${ }^{\S}$ Eugenio Magnani, ${ }^{\dagger}$ Stefania Pagliari, ${ }^{\S}$ \\ Giorgia Nardone, ${ }^{\dagger}$ Silvia Licoccia, ${ }^{\perp}$ Marilena Minieri, ${ }^{\dagger}$ Paolo Di Nardo, ${ }^{\dagger,+, *}$ and Enrico Traversa ${ }^{\perp, *}$
}

\begin{abstract}
${ }^{\dagger}$ Laboratory of Cellular and Molecular Cardiology, Department of Internal Medicine, University of Rome Tor Vergata, Rome, Italy, ${ }^{\ddagger}$ BioLink Institute, Link Campus University, Rome, Italy, ${ }^{\S}$ International Research Center for Materials Nanoarchitectonics (MANA), National Institute for Materials Science (NIMS), Tsukuba, Japan, and ${ }^{\perp}$ NAST Centre \& Department of Chemical Science and Technology, University of Rome Tor Vergata, Rome, Italy. "These authors contributed equally to this work.
\end{abstract}

$\mathrm{R}$ ecently, several nanomaterials currently used in different manufacturing domains have been scrutinized for their potential biomedical interest. ${ }^{1-3}$ Among others, special attention has been paid to cerium oxide $\left(\mathrm{CeO}_{2}\right.$, ceria) nanoparticles (nanoceria) that are currently used in industrial applications, such as catalysis, ${ }^{4}$ gas sensors, ${ }^{5}$ UV filters, ${ }^{6}$ and solid oxide fuel cells, ${ }^{7}$ for their unique property to store and release oxygen. ${ }^{8}$ This is due to the presence in ceria of a fraction of $\mathrm{Ce}$ ions in the $\mathrm{Ce}^{3+}$ valence state, simultaneously with $\mathrm{Ce}^{4+}$, with oxygen vacancies compensating for the lower positive charge. ${ }^{9}$ Nanoceria particles are more active with respect to the micrometer-sized counterpart because the defect concentration is increased at the surface, ${ }^{10}$ as confirmed also by theoretical studies. ${ }^{11}$ Therefore, ceria nanoparticles, where the larger surface area is associated with an increased number of oxygen vacancies and $\mathrm{Ce}^{3+}$ ions, showed enhanced catalytic properties ${ }^{12}$ and antioxidant capability in living systems. ${ }^{13-15}$ Moreover, a recent first-principles study showed that the vacancy concentration increases when ceria is exposed to water, which could be relevant in biological systems. ${ }^{16}$ In fact, under physiological conditions, the cell oxidative metabolism produces reactive oxygen species (ROS), such as superoxide anion radical $\left(\mathrm{O}_{2}^{\bullet-}\right)$, hydroxyl radical $\left(\mathrm{OH}^{\bullet-}\right)$, singlet oxygen $\left({ }^{1} \mathrm{O}_{2}\right)$, and hydrogen peroxide $\left(\mathrm{H}_{2} \mathrm{O}_{2}\right)$. ROS are unstable and highly reactive compounds able to extract electrons from cellular macromolecules to damage DNA and proteins and to modify membrane fatty acids, thus impairing major cell functions. ${ }^{17}$ Consistently, ROS are implied in the pathogenesis of several diseases, such as cancer, Parkinson's and Alzheimer's

\section{ABSTRACT}
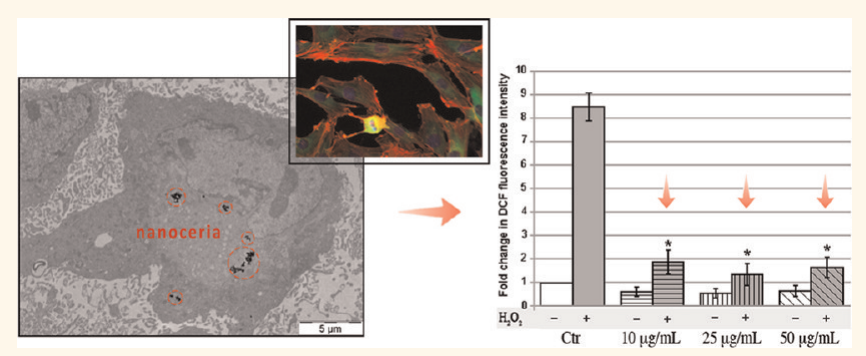

Cardiac progenitor cells (CPCS) are a promising autologous source of cells for cardiac regenerative medicine. However, CPC culture in vitro requires the presence of microenvironmental conditions (a complex array of bioactive substance concentration, mechanostructural factors, and physicochemical factors) closely mimicking the natural cell surrounding in vivo, including the capability to uphold reactive oxygen species (ROS) within physiological levels in vitro. Cerium oxide nanoparticles (nanoceria) are redox-active and could represent a potent tool to control the oxidative stress in isolated CPCs. Here, we report that $24 \mathrm{~h}$ exposure to 5, 10, and $50 \mu \mathrm{g} / \mathrm{mL}$ of nanoceria did not affect cell growth and function in cardiac progenitor cells, while being able to protect $\mathrm{CPCs}$ from $\mathrm{H}_{2} \mathrm{O}_{2}$-induced cytotoxicity for at least 7 days, indicating that nanoceria in an effective antioxidant. Therefore, these findings confirm the great potential of nanoceria for controlling ROS-induced cell damage.

KEYWORDS: cerium oxide $\cdot$ nanoparticles $\cdot$ nanoceria $\cdot$ cardiac progenitor cells . reactive oxygen species $\cdot$ oxidative stress

diseases, cardiovascular dysfunctions, inflammatory conditions, and aging. ${ }^{18-21}$ On the other hand, intracellular antioxidative defense systems consisting of enzymatic (i.e., superoxide dismutase, SOD, and catalase) and non-enzymatic (i.e., vitamins $C$ and $E$, thiols, and glutathione) components modulate ROS intracellular levels to regulate, as second messengers, cell growth and differentiation. ${ }^{22}$

Recent investigations have shown that ceria nanoparticles could scavenge ROS and act as a catalyst mimicking the activity

\section{* Address correspondence to dinardo@uniroma2.it, traversa@uniroma2.it.}

Received for review December 8, 2011 and accepted April 23, 2012.

Published online April 23, 2012 $10.1021 / \mathrm{nn} 2048069$

(c) 2012 American Chemical Society 
of SOD, the enzyme that catalyzes the dismutation of the superoxide radical anion in living cells, ${ }^{23,24}$ and also possess a catalase-like activity with the ability to decompose $\mathrm{H}_{2} \mathrm{O}_{2}$ to $\mathrm{O}_{2}$ and $\mathrm{H}_{2} \mathrm{O}^{25}$ The analysis on two leukocyte cell lines, undergoing apoptosis via redoxdependent or independent mechanisms, revealed that the intracellular antioxidant effect is the direct cause of the anti-apoptotic and pro-survival effects of nanoceria in vitro: nanoceria only affects the redox-dependent apoptosis by means of $\mathrm{Ce}^{3+} / \mathrm{Ce}^{4+}$ redox reactions. ${ }^{26}$ Furthermore, when embedded into poly(lactic-coglycolic acid) (PLGA) films, ceria nanoparticles enhance the adhesion and growth of adult cardiac progenitor cells (CPCs), driving their orientation into specific directions. $^{2}$

Adult progenitor cells are precursors of all differentiated cells within a specific germ layer and are located in almost every district of the body, where they are responsible for the physiological cell turnover and tissue repair. Progenitor cells are surviving in special tiny regions of each tissue in which a critical environment (niche) is maintained by the surrounding cells. In these conditions, progenitor cells can self-renew or can be committed to a specific cell lineage. ${ }^{27}$ In the myocardium, evidence for progenitor cell differentiation and cardiomyocyte turnover is given, but such processes appear modest and not sufficient to match the tissue needs, when an extensive heart damage occurs, as in myocardial infarction. ${ }^{28,29}$ Nevertheless, many attempts at expanding cardiac progenitor cells in vitro have been undertaken to generate a sufficient number of suitable cells to set up clinically efficient and costeffective treatments. ${ }^{30}$ Progenitor cell culture in vitro requires the presence of microenvironmental conditions closely mimicking the natural cell surrounding in vivo (niche). ${ }^{31,32}$ Among others, the antioxidant systems are fundamental to maintain ROS within physiological levels in vitro. ${ }^{33}$ Ceria nanoparticles, either dispersed into the culture medium or embedded into the scaffold material, could represent a potent tool to control the oxidative stress in isolated cardiac progenitor cells.

The present study was designed to verify to which extent ceria nanoparticles could contribute to control the oxidative stress and growth of adult cardiac progenitor cells. The $\mathrm{CeO}_{2}$ nanoparticles used were the same described in previous works, ${ }^{2,26}$ having size in the 5-8 $\mathrm{nm}$ range. In particular, the effects induced by different amounts of nanoceria on $\mathrm{Lin}^{\text {neg }} / \mathrm{SCa}-1^{\text {pos }} \mathrm{CPCS}$ challenged with a potent cell oxidant agent, $\mathrm{H}_{2} \mathrm{O}_{2}$, were investigated in terms of cyto-compatibility, internalization, and cell morphology and differentiation. Such cells are shown to be negative for the expression of mature hematopoietic cell lineage markers $\left(\mathrm{Lin}^{\text {neg }}\right)$ but positive for the stem cell antigen-1, Sca-1 $\left(\mathrm{Sca}-1^{\text {pos }}\right)$, marker associated with multipotency and self-renewal in bone marrow and heart. ${ }^{34,35}$

\section{RESULTS}

Nanoceria Is Internalized by CPCs. In order to define the fate of nanoceria particles in CPCs after 7 day culture, ultrastructural analysis was performed to detect and localize the nanoparticles within the cells, after $24 \mathrm{~h}$ exposure to 10,25 , and $50 \mu \mathrm{g} / \mathrm{mL} \mathrm{CeO}_{2}$, as described in the Materials and Methods section. Figure 1 shows typical TEM micrographs of $\mathrm{Lin}^{\text {neg }} / \mathrm{Sca}-1^{\text {pos }}$ CPCs (hereafter referred to as CPCs) after treatment with $50 \mu \mathrm{g} / \mathrm{mL} \mathrm{CeO}_{2}$, as a representative example. Cerium oxide nanoparticles were uptaken by CPCs and were retained inside the cytoplasm as clusters of aggregated particles, not encapsulated by vesicular membranes.

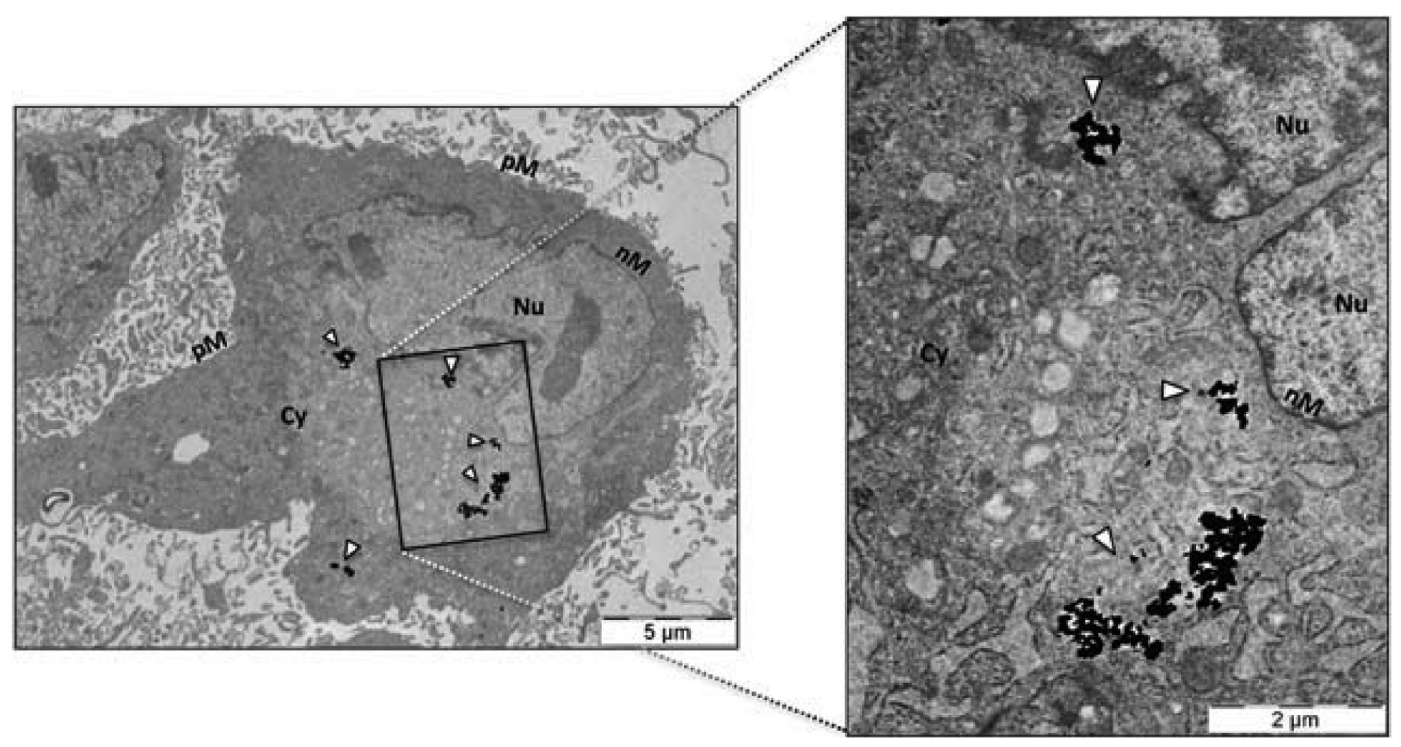

Figure 1. TEM micrographs of Sca- ${ }^{\text {pos }}$ CPCs. The images illustrate the presence of clusters of ceria nanoparticles (white arrows) inside the cytoplasm, and they are representative of $50 \mu \mathrm{g} / \mathrm{mL} \mathrm{CeO}_{2}$ treatment after 7 days. Magnification: $3400 \times$ (left) and $11500 \times$ (right); $\mathrm{pM}=$ plasma membrane, $\mathrm{nM}=$ nuclear membrane, $\mathrm{Cy}=$ cytoplasm, $\mathrm{Nu}=$ nucleus. 

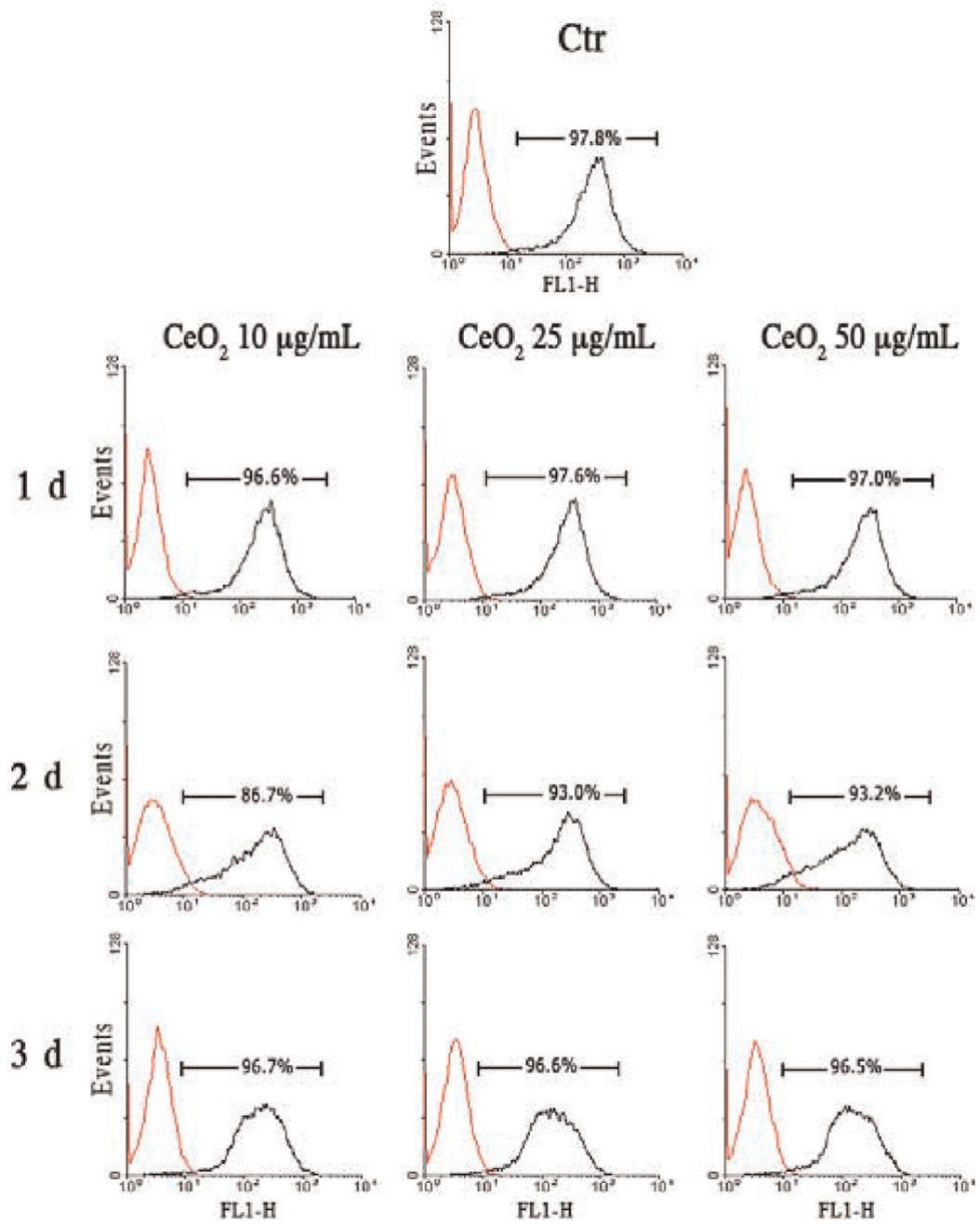

Figure 2. Sca-1 expression in $\mathrm{CeO}_{2}$-treated $\mathrm{CPCs}$ analyzed by fluorescence activated cell sorter. $\mathrm{CPCs}$ preserved their stemness phenotype at all of the concentrations considered at 1,3, and 7 days from nanoceria administration. Red curves represent the negative control obtained by incubating Sca- $1^{\text {pos }}$ CPCs in the absence of anti-Sca- 1 antibody. One representative image of Sca-1 expression in untreated CPCs (control, $\mathrm{Ctr}$ ) at $24 \mathrm{~h}$ after the beginning of the experiment is given; same results were obtained at 3 and 7 days. The logarithm on the $X$-axis (FL1-H channel) represents the intensity of fluorescent signal; cell number is given on the $Y$-axis (Events). The data are representative of three independent experiments performed in the same conditions.

Nanoceria Does Not Alter CPC Phenotype and Growth. After $24 \mathrm{~h}$ ceria stimulus, the expression of the Sca-1 antigen was preserved in a high percentage of CPCs throughout the culture (Figure 2). Moreover, the immunofluorescence analysis indicated that the morphology of $\mathrm{CeO}_{2}$-treated versus untreated CPCs was not modified, as shown by phalloidin staining of actin filaments (Figure $3 a-d)$. In fact, treated CPCs exhibited a wellorganized cytoskeleton and proper focal adhesions, as demonstrated by the typical expression of vinculin, a protein associated with cell-cell and cell-extracellular matrix (ECM) junctions. Furthermore, after a single initial nanoceria exposure, CPCs counts at 1, 3, and 7 days displayed a time-response but not a doseresponse effect (Figure 3e).

CPC Differentiation Is Not Altered by Nanoceria Exposure. A hallmark of the stemness status is cell pluri/multipotency, that is, the ability to generate different cell phenotypes when progenitor cells are challenged with appropriate stimuli. To confirm their abided multipotency, nanoceria-treated CPCs were cultured in adipogenic or osteogenic media. After 10 days, lipid vacuoles or calcium deposits were detected in cell cytoplasm, thus demonstrating that the nanoceria treatment did not interfere with progenitor cell ability to proceed toward adipogenic (Figure $4 \mathrm{a}-\mathrm{d}$; scale bar $=20 \mu \mathrm{m}$ ) or osteoblastic (Figure $4 \mathrm{e}-\mathrm{h}$ ) lineages.

Furthermore, when directly cocultured with murine neonatal cardiomyocytes, nanoceria-treated Vybrantred-labeled CPCs proceeded to cardiac commitment within 10 days. In fact, CPCs displayed an upregulated expression of GATA-4, the membrane translocation of connexin 43, and, more interestingly, the expression of the $\alpha$-sarcomeric actinin (Figure $4 \mathrm{i}-\mathrm{t}$ ). Differentiation in nontreated CPCs cocultured with murine neonatal cardiomyocytes was as expected and already reported 

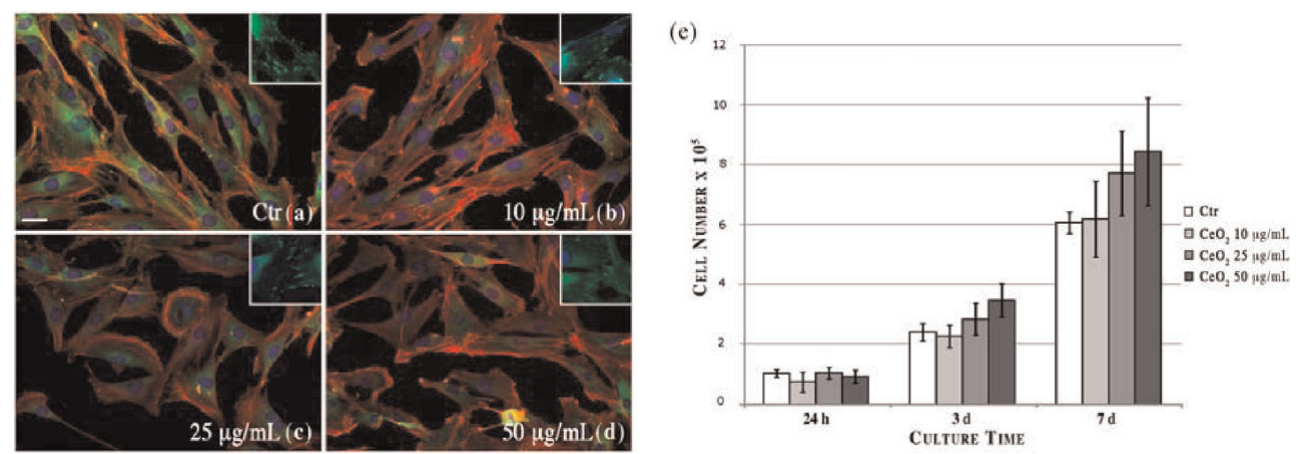

Figure 3. Effects of $\mathrm{CeO}_{2}$ nanoparticles on $\mathrm{CPC}$ morphology and growth. $\mathrm{CeO}_{2}$ - untreated or treated cells [Ctr (a), $10 \mu \mathrm{g} / \mathrm{mL}(\mathrm{b})$, $25 \mu \mathrm{g} / \mathrm{mL}$ (c), and $50 \mu \mathrm{g} / \mathrm{mL}$ (d)] show a well-organized cytoskeleton and good cell-cell and cell-surface interactions, as demonstrated by staining F-actin filaments with rhodamine-labeled phalloidin (red) and antivinculin antibody (green), respectively. Insets at the top right: detail of cell focal adhesions. Similar results were obtained after 3 and 7 days in culture. Scale bar $=15 \mu \mathrm{m}$. (e) $\mathrm{CPC}$ growth in the presence of different $\mathrm{CeO}_{2}$ concentrations. Cell number evaluated at 1,3 , and 7 days after $24 \mathrm{~h}$ exposure to nanoceria. The differences among treated and untreated (Ctr) cells were not significant $(p>0.05)$. The values are expressed as means \pm SD of three independent measurements.

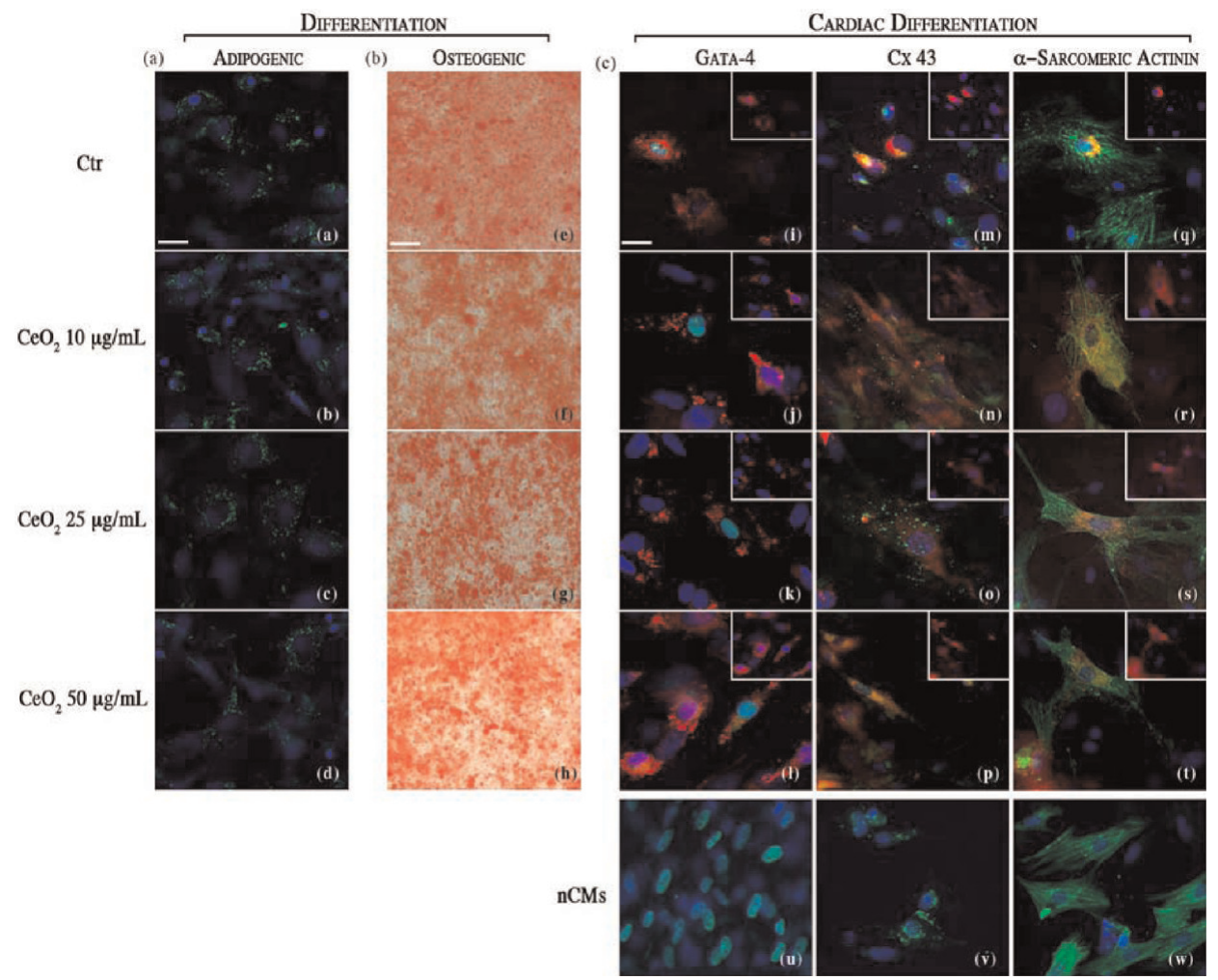

Figure 4. Sca- ${ }^{\text {pos }}$ CPCs adipogenic, osteogenic, and cardiac differentiation in the presence of different concentrations of $\mathrm{CeO}_{2}$. Adipogenic differentiation ( $\mathrm{a}-\mathrm{d}$ ) was evidenced by the formation of intracytoplasmatic lipid vacuoles (green), stained with AdipoRed. Scale bar $=15 \mu \mathrm{m}$. Osteogenic differentiation $(\mathrm{e}-\mathrm{h})$ was demonstrated by calcium deposits (red) which were shown by Alizarin Red S staining. Scale bar $=150 \mu \mathrm{m}$. For cardiac differentiation $(i-t)$, Sca- ${ }^{\text {pos }}$ CPCs were pretreated with vital Vybrant dye (red) and put in coculture with nCMs for 10 days. Treated CPCs preserved their ability to acquire typical cardiac markers (GATA-4, Cx 43, and $\alpha$-sarcomeric actinin, in green). Nontreated CPCs and $\mathrm{nCMs}(\mathrm{u}-\mathbf{w})$ were used as positive controls. Nuclei were labeled with DAPI (blue). Scale bar $=15 \mu \mathrm{m}$.

previously ${ }^{32}$ and not significantly different with respect to the $\mathrm{CeO}_{2}$-treated CPCs (Figure $4 \mathrm{u}-\mathrm{w}$ ).

Nanoceria Protects CPCs from 0xidative Insults. The ceria antioxidant effects were assessed in CPCs exposed to ROS generation and oxidative stress by $\mathrm{H}_{2} \mathrm{O}_{2}$. As shown in Figure 5, no significant differences in ROS production were detectable in CPCs preincubated with nanoceria for $24 \mathrm{~h}$, as compared to control, thus suggesting that $\mathrm{CeO}_{2}$ did not promote ROS generation. Instead, a significant decrease in the intensity of DCF fluorescence, indicating that the ROS content was attenuated, was observed when CPCs were challenged with $\mathrm{H}_{2} \mathrm{O}_{2}$, after $24 \mathrm{~h}$ pretreatment with $50 \mu \mathrm{g} / \mathrm{mL}$ nanoceria, but not with the smaller concentrations (10 and $25 \mu \mathrm{g} / \mathrm{mL}$ ). By contrast, a significant decrease in CPC intracellular ROS levels was detectable when the effects of 25 and 

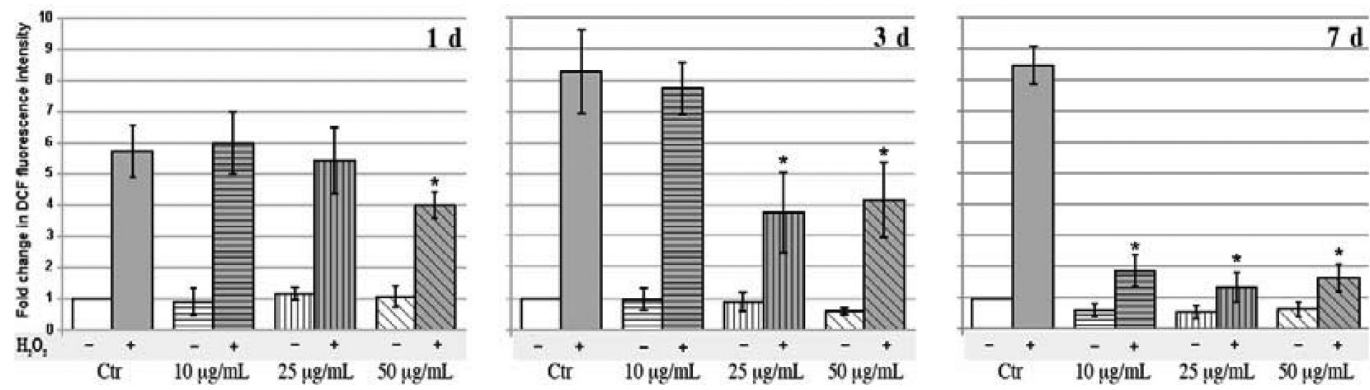

Figure 5. ROS production in Sca-1 ${ }^{\text {pos }}$ CPCs exposed to $\mathrm{H}_{2} \mathrm{O}_{2}$. The results indicated a time-dependent decrease in ROS production when the cells were pretreated with different concentrations of $\mathrm{CeO}_{2}$, as assessed by DCF fluorescence $\left(^{*}: \mathrm{H}_{2} \mathrm{O}_{2^{-}}\right.$ treated cells vs $\mathrm{CeO}_{2}-\mathrm{H}_{2} \mathrm{O}_{2}$-treated cells). ROS levels in the control group were arbitrarily set at fluorescence value of 1 . All data are expressed as means \pm SD of three independent experiments and each repeated in triplicate. The relative SD of the samples has been calculated after normalization of the values compared to the mean values of the $\mathrm{CeO}_{2}$ untreated control (negative) $(p<0.05)$.

$50 \mu \mathrm{g} / \mathrm{mL} \mathrm{CeO}_{2}$ administered as single initial $24 \mathrm{~h}$ pulse were allowed to proceed for 3 days before the $\mathrm{H}_{2} \mathrm{O}_{2}$ stimulus. Moreover, a reduced ROS production was observed when $\mathrm{H}_{2} \mathrm{O}_{2}$ was added to the culture medium 7 days after the nanoceria pretreatment, independently from the nanoparticle dose (Figure 5).

\section{DISCUSSION}

Nanoparticles are actively scrutinized for their potential noxious effects in living systems ${ }^{36-38}$ and also for some characteristics potentially exploitable for biotechnological and clinical purposes. ${ }^{1,3,39,40}$ However, current knowledge is still unsystematic and restricted to particular aspects of nanoparticles' capability to induce toxic and pathological processes or to alter structure and function in different cell types. ${ }^{41-43}$ Nevertheless, among nanoparticles, ceria is redox-active and has shown potential for antioxidant therapies controlling ROS levels. ${ }^{44}$ This nanoceria characteristic could also be deployed to maintain ROS balance in progenitor cells used for reconstructing in vitro cardiac tissues. ${ }^{45}$

In this context, no study has been so far carried out to define nanoparticle effects on cardiac progenitor cell structure and function, to the best of our knowledge. Stem/progenitor cells are particularly sensitive to environmental factors, ${ }^{46}$ and the presence of alien particles inside the cytoplasm or in the nearby extracellular space could cause major perturbations in their behavior and fate. Indeed, present findings demonstrated that CPCs resident into the heart were prone to uptake cerium oxide nanoparticles as aggregates, seemingly floating in the cytosol, while no evidence of encapsulation or particle translocation inside vesicles or organelles ${ }^{44}$ was found by electron microscopy after 7 days from ceria administration. Furthermore, freefloating intracellular ceria nanoparticles did not alter the CPC cytoskeleton, as defined by F-actin filaments and DAPI-stained nuclei, and no apparent intracellular signs (nanoparticle encapsulation, etc.) were detectable that could suggest that nanoparticles could be removed or inactivated. As a matter of fact, after a single administration, CPCs underwent a stable and permanent ceria colonization that was not maintained by a continued nanoparticle supply from the extracellular compartment and did not provoke apparent cell structural damages.

The integrity of ceria-intruded CPCs was also confirmed by the preserved Sca-1 expression and multilineage potential. In fact, despite the persistent presence of ceria nanoparticles into the cytosol, CPCs retained the capability to multidifferentiate and, when properly cocultured with neonatal cardiac cells, to adopt the cardiomyocyte phenotype, as demonstrated by the expression of cardiac-specific proteins, such as the $\alpha$-sarcomeric actinin in newly formed sarcomeres, GATA-4, a cardiac nuclear transcription factor, and connexin 43, a gap junction protein, which is necessary to establish cardiomyocyte electromechanical junctions. In addition, ceria did not affect CPC survival or growth in vitro. Finally, the nanoparticle inertness in interacting with CPC intracellular physicochemical mechanisms was confirmed by the ceria inability to modify basal ROS levels and to induce cytotoxicity, as described in other mammalian cell types. ${ }^{47,48}$ Taken together, ceria nanoparticles uptaken during $24 \mathrm{~h}$ pulse persisted for the total length (7 days) of the experiments inside CPCs cultured in a standard medium deprived of nanoparticles; nonetheless, they did not induce apparent structural and functional cell modifications. However, in several cell types, nanoceria plays an antioxidant and antiapoptotic role related to the presence of $\mathrm{Ce}^{3+}$ ions. ${ }^{13-15,26}$ Moreover, in a more recent in vivo study, a combination of nanoceria and sodium selenite improved diabetes-induced oxidative stress in a murine model of diabetes. ${ }^{49}$ For CPCs, internalized ceria antioxidant effects emerged only when cells were exposed to an oxidative stress induced by $\mathrm{H}_{2} \mathrm{O}_{2}$ and were dose- and time-dependent. Following a $24 \mathrm{~h}$ single pulse, $50 \mu \mathrm{g} / \mathrm{mL}$ ceria nanoparticles displayed a time-dependent incrementing capability to decrease ROS levels by 30,50 , and $75 \%$ after 1,3 , and 
7 days, respectively. Instead, pulses with smaller nanoparticle doses (10 and $25 \mu \mathrm{g} / \mathrm{mL}$ ) needed a longer dose-related activation time to express their antioxidant capability. In fact, $25 \mu \mathrm{g} / \mathrm{mL}$ nanoceria antioxidant activity was displayed only after 3 days ( $50 \%$ reduction as compared with untreated cells) and was maximal at 7 days (-80\%), while $10 \mu \mathrm{g} / \mathrm{mL} \mathrm{CeO}_{2}$ preloading attenuated ROS production $(-70 \%)$ exclusively at 7 days.

These findings clearly demonstrated that uptaken ceria nanoparticles are a potent antioxidant agent and $\mathrm{CeO}_{2}$ preloading attenuates ROS production over time to levels not significantly different from basal values in untreated cells. This observation is extremely relevant since no investigation before demonstrated that, after an unpredictable time interval, even low intracellular nanoparticle doses can induce effects undetectable by conventional, although sophisticated, analysis protocols. In stem cells, this possibility is particularly critical since ROS baseline levels and genomic instability are closely related, and the balance between ROS concentration and antioxidant agents is fundamental to preserve the cellular systems devoted to DNA repair ${ }^{50}$ and the ROS key role in intracellular signaling. ${ }^{22}$

These findings are very promising for the use of nanoceria in regenerative medicine ${ }^{51}$ since an adequate presence of ceria nanoparticles embedded into the scaffold or into cells could contribute, limiting the generation of ROS, to create the most favorable artificial microenvironment to maintain cardiac progenitor cells in optimal conditions during in vitro tissue growth. The results suggest that the effective nanoceria dose may be represented by the amount of uptaken nanoparticles, in fact after $24 \mathrm{~h}$ exposure, the extracellular nanoceria was removed by repeated washings and the protective effects occurred in the presence of cytosolic nanoparticles even 3 and 7 days after nanoceria removal. However, a proper dose has to be determined; otherwise, the delayed effects induced by low doses of ceria could be ineffective to adequately protect cells against an excess of ROS.

Another noteworthy finding is the long-term antioxidant action of nanoceria, unprecedented in the conventional antioxidant drugs, ${ }^{26}$ which is persistent up to 7 days and only due to the nanoparticles uptaken from the cells, as confirmed by the untreated controls. We speculate that this could be related to a possible autoregenerative reactive cycle of cerium very likely activated in vitro, ${ }^{44}$ thus allowing a continuous regeneration of the antioxidant activity, which could favor its activity over time with a single nanoparticle administration. Among the different hypotheses formulated to explain the ceria antioxidant mechanisms, as stated above, recent abiotic investigations suggested that nanoceria could have a SOD-like activity when a large $\mathrm{Ce}^{3+}$ fraction is present, ${ }^{23,24}$ while a catalase-like activity is shown for nanoceria preparations with a large $\mathrm{Ce}^{4+}$ fraction. ${ }^{25}$ The two redox reactions combined allow a continuous regeneration of the nanoceria antioxidant activity, potentially abating all noxious intracellular ROS via a self-regenerating mechanism, which could be enacted over time with a single nanoparticle administration. ${ }^{44}$ The present findings might be the first experimental demonstration in a biological system of the nanoceria self-regenerating antioxidant mechanism. Nonetheless, the present time course experiments did not exclude that, in the long run, intracellular conditions, such as $\mathrm{pH}$ fluctuations or specific enzyme actions, could vary the surface $\mathrm{Ce}$ valence state, so contributing to both catalase and SOD mimetic activity.

Present findings showed that time exposure to nanoparticles could be a major factor in ceria efficiency; in fact, nanoceria induced the same effects in ROS levels in time intervals inversely related to doses. Further studies are needed to fully understand this issue, although this could imply that a "threshold" must be reached in intracellular ceria physicochemical interactions before the antioxidant effects could emerge. In this respect, differences in nanoparticle synthesis techniques, size, shape and charge, dosage and exposure time, administration procedures, mechanisms of cellular uptake, and intracellular trafficking could be critical to induce ceria beneficial effects and to explain some conflicting results so far reported about ceria action in biological systems. ${ }^{3,47,52}$ Moreover, the influence of culture medium components on nanoparticle charge and cell uptake and, thus, on their biological activity, also remains to be addressed. ${ }^{53-55}$ However, all of these hypotheses need to be investigated more in-depth to exhaustively elucidate the time-dependent biological mechanisms supporting ceria antioxidant behavior.

The findings suggest another observation: the observed mechanism could imply that nanoparticles endowed with specific biological activities could remain silent inside cells for a long time interval, provided that they will not be degraded in biological fluids, and be eventually activated by slight intraand/or extracellular environmental modifications. This phenomenon could envisage a new and unexpected scenario in the relationship between nanoparticles and cells. In fact, the interactions can be beneficial, triggering potential therapeutic effects like in the case of nanoceria, but can also be noxious with different nanoparticles. Due attention must be paid to assess the actuality of this perspective.

\section{CONCLUSIONS}

Unprecedented long-term protection from oxidative stresses, up to 7 days, of cardiac progenitor cells was demonstrated for internalized ceria nanoparticles after a $24 \mathrm{~h}$ initial treatment, without further contacts between CPCs and nanoceria. The internalized 
nanoceria particles, which are inert with respect to CPC homeostasis and differentiation, remain apparently silent inside CPCs when compared with related controls and in the context of the present investigation and, in due course, act as a defense upon oxidative insults. The abatement of intracellular ROS may be due to a self-regenerating mechanism for nanoceria, involving redox cycles between the $\mathrm{Ce}^{3+}$ and $\mathrm{Ce}^{4+}$ oxidation states that react with superoxide and hydrogen peroxide, mimicking the role of the two key antioxidant enzymes, SOD and catalase. The present findings might be the first experimental demonstration in a biological system of this self-regenerating antioxidant

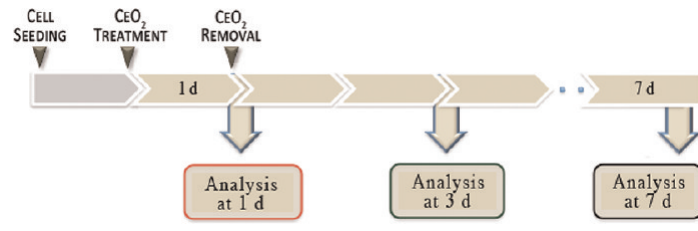

Scheme 1. Scheme of the experimental design used to test the $\mathrm{CeO}_{2}$ antioxidant properties. Sca- $1^{\text {pos }} \mathrm{CPCs}$ were treated with different concentrations of $\mathrm{CeO}_{2}$ nanoparticles $(10,25$, and $50 \mu \mathrm{g} / \mathrm{mL}$ ) for $24 \mathrm{~h}$. Following a single $\mathrm{CeO}_{2}$ exposure, cells were subjected to analysis at 1, 3, and 7 days.

mechanism, previously postulated for nanoceria from abiotic measurements.

\section{MATERIALS AND METHODS}

All experimental procedures and protocols used in this investigation were approved by the institutional Animal Care and Use Committee of the University of Rome Tor Vergata (Rome, Italy).

Isolation and Culture of Murine CPCs. CPCs were extracted from whole hearts derived from female B57/BI mice (6 weeks old) housed under standard conditions. The myocardial tissue was delicately minced with a bistoury and incubated overnight at $4{ }^{\circ} \mathrm{C}$ with $0.05 \%$ trypsin in a solution of $0.02 \%$ EDTA in phosphate-buffered saline (PBS). Subsequently, trypsin inhibitor (Worthington Biochemical Corporation, Lakewood, NY, http://www.worthington-biochem.com) was used to block the enzymatic reaction, and tissue fragments were incubated in collagenase II $(1500 \mathrm{U})$ in Leibovitz medium (Worthington Biochemical Corporation) for $30 \mathrm{~min}$ at $37^{\circ} \mathrm{C}$. Afterward, the fragments were centrifuged for $10 \mathrm{~min}$ at $800 \mathrm{~g}$, and the pellet was resuspended in DMEM (Dulbecco's modified Eagle's medium, Lonza, Walkersville, USA, Cat. No. BE12-614F) supplemented with $10 \%$ fetal bovine serum (FBS), $100 \mathrm{IU} / \mathrm{mL}$ penicillin, and $10 \mu \mathrm{g} / \mathrm{mL}$ streptomycin (Lonza; hereafter referred to as complete medium, http://bio.lonza.com/testpages-archive/ cell-transfection-db/culture-media-database/\#ext-comp-1003: tab 20:change), filtered through a $70 \mu \mathrm{m}$ cell strainer (Falcon BD, Franklin Lakes, NJ, http://www.bdbiosciences.com), and incubated at $37{ }^{\circ} \mathrm{C}$ and $5 \% \mathrm{CO}_{2}$. After $24 \mathrm{~h}$, the medium and the nonadhering fragments were removed and replaced with fresh medium. Cardiomyocytes were removed by changing the medium every day. After 10-15 days, fibroblastoid cells spontaneously migrated out from the fragments and reached confluence. These nonmyocytic cells (NMCs) were trypsinized and harvested.

NMC lineage positive ( Lin $^{\text {pos }}$ ) fractions were eliminated by a magnetic cell sorting protocol (Miltenyi Biotec $\mathrm{GmbH}$, Bergisch Gladbach, Germany) in order to obtain the lineage negative fraction ( Lin $^{\text {neg }}$ ) of cell population. Briefly, cells were incubated with a cocktail of biotin-conjugated monoclonal antibodies (CD5, CD45R (B220), CD11b, anti-Ly-6G (Gr-1), 7-4, and Ter119) and then separated by anti-biotin microbead-conjugated secondary antibody. The $\operatorname{Lin}^{\text {neg }}$ fraction was resuspended in complete medium. Cell concentration was adjusted at $1.5 \times 10^{4}$ cells $/ \mathrm{cm}^{2}$ and expanded in culture.

Purification of Sca-1 ${ }^{\text {pos }}$ CPCs. The Lin ${ }^{\text {neg }} / \mathrm{Sca} 1^{\text {pos }}$ fraction of CPCs (CPCs) was enriched by means of an immunomagnetic protocol. Briefly, the cells were detached from the dish surface by trypsin incubation, washed twice with PBS, and incubated with a microbead-conjugated antibody directed against the Sca-1 antigen. An aliquot of the purified cell subpopulations $\left(\mathrm{Sca}-1^{\text {pos }}, \mathrm{Sca}-1^{\text {neg }}\right)$ was then stained with anti-Sca-1-FITC antibody (BD Pharmingen, Cat. No. 553335) for 20 min in ice cold PBS at $4{ }^{\circ} \mathrm{C}$, centrifuged for $10 \mathrm{~min}$ at $800 \mathrm{~g}$, and resuspended in cold PBS. Green fluorescence of the samples was registered using a FACScalibur flow cytometer (BD Biosciences, CA, USA). The results were analyzed using WinMDI 2.8 software.

$\mathrm{Ce}_{2}$ Nanopowder Treatment. $\mathrm{CeO}_{2}$ nanopowders, resuspended in ultrapure deionized $\mathrm{H}_{2} \mathrm{O}$, were produced and characterized as already described elsewhere. ${ }^{3,8,27}$ The suspensions were freshly prepared, previously sonicated (Bandelin, Sonorex super RK 514 BH; Berlin, Germany) for 1 h, and immediately administered to the cells. CPCs (p7) were seeded at the concentration of $1.5 \times 10^{5} / \mathrm{cm}^{2}$ in complete medium and maintained at $37{ }^{\circ} \mathrm{C}$ in $5 \% \mathrm{CO}_{2}$ atmosphere. After $24 \mathrm{~h}$, the cells were untreated (negative control) or treated with 10,25 , or $50 \mu \mathrm{g} / \mathrm{mL}$ of $\mathrm{CeO}_{2}$ nanopowder. Then, the cells were incubated for an additional $24 \mathrm{~h}$, washed to remove the nanoceria powder, incubated with fresh medium, and analysis performed at various time intervals. Scheme 1 describes the experimental protocol used to assess the effects onto cardiac precursor cells of various nano- $\mathrm{CeO}_{2}$ concentrations at 1,3 , and 7 days after starting the exposure to nanoparticles.

Transmission Electron Microscopy (TEM) Analysis. To investigate intracellular $\mathrm{CeO}_{2}$ localization, CPCs were cultured in T25 flasks (Falcon BD) at the density of $2.0 \times 10^{5}$ cells $/ \mathrm{cm}^{2}$ in DMEM $10 \%$ FBS and treated with 10,25 , and $50 \mu \mathrm{g} / \mathrm{mL}$ nanoceria for $24 \mathrm{~h}$ at $37{ }^{\circ} \mathrm{C}$ in $5 \% \mathrm{CO}_{2}$ atmosphere. Afterward, cells were washed three times with PBS, incubated for an additional 7 days, and the medium was replaced by fresh medium at least every 2 days. Then, cells were detached by trypsin treatment, centrifuged, washed with PBS, and fixed overnight in $2.5 \%$ glutaraldehyde in $0.2 \mathrm{M}$ phosphate buffer $(\mathrm{pH}=7.2)$. The samples were postfixed with $1 \%$ osmium tetroxide (Merck, Germany) for $2 \mathrm{~h}$ and dehydrated in an ethanol series: 50, 75, 95 and $100 \%(\times 2)$ for $10 \mathrm{~min}$. Subsequent passages in $100 \%$ alcohol and propylene oxide (1:1) and absolute propylene oxide were conducted. Then, the samples were embedded in growing resin (EPON 812, EMS USA) concentrations and placed in a $60^{\circ} \mathrm{C}$ oven for $72 \mathrm{~h}$. Finally, 30-50 $u \mathrm{~m}$ sections were cut with an ultramicrotome, double stained with uranyl acetate-lead citrate, and examined in a Philips CM120 transmission electron microscope (TEM), operated at $60 \mathrm{kV}$ and equipped with a Philips Megaview III video camera. Images were electronically captured by AnalySys 2.0 software and composed in an Adobe Photoshop CS4 format.

Immunofluorescence Analysis of $\mathrm{Ce}_{2}$-Treated CPC Morphology and Cardiac Differentiation. $\mathrm{CeO}_{2}$-treated $\mathrm{CPCs}$ were seeded at the concentration of $2 \times 10^{4}$ cells $/ \mathrm{cm}^{2}$ on chamber slides, washed in PBS, fixed in $4 \%$ paraformaldehyde (PFA) in PBS containing $\mathrm{CaCl}_{2}$ for 30 min at $4{ }^{\circ} \mathrm{C}$, and permeabilized with $0.1 \%$ Triton $\mathrm{X}-100$. Cells were incubated with tetrarhodamine-conjugated phalloydine (Invitrogen Corp., Carlsbad, CA, http://www. invitrogen.com), antivinculin, anti-GATA-4, anticonnexin-43, and anti- $\alpha$-sarcomeric actinin antibodies (Sigma-Aldrich, St. Louis, MO) in $1 \%$ PBS-BSA for $1 \mathrm{~h}$ at room temperature. The appropriate fluorophore-conjugated secondary antibodies were used. Nuclei were stained with 4',6'-diamidino-2-phenylindole 
(DAPI). Secondary antibodies in the absence of a specific primary antibody were used to exclude the occurrence of unspecific signals. The images were taken using a Leica DMRB microscope equipped with a digital camera.

Cell Counts. After $24 \mathrm{~h}$ ceria treatment, the first count (referred as day 1 ) was performed. Then, the cells were counted at days 3 and 7 after the initial nanoceria treatment. For cell counts, CPCs were detached by using a solution containing $0.05 \%$ trypsin in $0.02 \%$ EDTA. After stopping the reaction with complete medium, cells were centrifuged for $10 \mathrm{~min}$ at $800 \mathrm{~g}$. The pellet was resuspended in complete medium, and counts were performed by trypan blue exclusion method with Neubauer chamber. Each count was repeated at least three times.

Differentiation Protocols. Lin ${ }^{\text {neg }} / \mathrm{Sca}-1^{\text {pos }} \mathrm{CeO}_{2}$-treated CPCs (p7) were seeded onto $35 \mathrm{~mm}$ dishes in complete medium. After $24 \mathrm{~h}$, the medium was removed and the cells were cultured in standard adipogenic (Lonza, Cat. No PT3102B, http://bio.lonza. com/3018.html\#ext-comp-1003:tab15:change) ${ }^{56}$ or osteogenic (DMEM $10 \%$ supplemented with $50 \mu \mathrm{g} / \mathrm{mL}$ ascorbic acid, $10 \mathrm{mM}$ $\beta$-glycerophosphate, and $10 \mathrm{nM}$ dexamethasone; all from SigmaAldrich $)^{57}$ medium for 10 days.

Adipogenic Differentiation. Adipogenic differentiation was assessed by AdipoRed lipid assay reagent (Lonza, Cat. No PT7009). Briefly, cells cultured in adipogenic medium were incubated for 20 min in AdipoRed solution, and the presence of lipid vacuoles was visualized under a fluorescence microscope.

Osteogenic Differentiation. Osteogenic differentiation was assessed by staining cells with Alizarin Red S for 20 min, and the production of calcium deposits was confirmed with light microscopy.

Cardiac Differentiation. We followed an in vitro cardiac differentiation protocol previously developed, using neonatal cardiomyocytes (nCMs) isolated from 1 to 3 day old neonatal murine hearts of C57/BI6 mice. ${ }^{33}$ For coculture experiments, $\mathrm{nCM}$ preparation was plated at a density of $5.0 \times 10^{4}$ cells $/ \mathrm{cm}^{2}$ onto precoated glass chamber slides (Nalgene, Nunc International). The day after, $\mathrm{CPCs}$ treated with different $\mathrm{CeO}_{2}$ concentrations for $24 \mathrm{~h}$ were prestained with viable red fluorescent dye Vybrant Dil (Molecular Probes, Eugene, OR) following the manufacturer's specifications and seeded directly onto cardiomyocytes at a 1:5 ratio in complete medium. The medium was changed every other day throughout the entire experiment. Cells were cocultured for 10 days before being processed for immunofluorescence analysis. Control CPCs without pretreatment with $\mathrm{CeO}_{2}$ were prepared in the same conditions and used as a control.

Intracellular ROS Induction and Determination. ROS were induced in $1.5 \times 10^{4}$ cells $/ \mathrm{cm}^{2} \mathrm{CPCs}$ by $50 \mu \mathrm{M} \mathrm{H}_{2} \mathrm{O}_{2}$ treatment for $30 \mathrm{~min}$ in DMEM $10 \%$ serum after being exposed for $24 \mathrm{~h}$ to 10,25 , and $50 \mu \mathrm{g} / \mathrm{mL}$ of $\mathrm{CeO}_{2}$. To quantify ROS production, the $2^{\prime}, 7^{\prime}-$ dichlorfluorescein diacetate (DCFH-DA) method was used. ${ }^{58}$ DCFH-DA is a membrane-permeant compound and, once inside the cell, it is deacetylated by endogenous esterases to form the nonfluorescent $2^{\prime}, 7^{\prime}$-dichlorfluorescein (DCFH). Next, DCFH is converted to fluorescent dichlorofluorescein (DCF) compound by the action of cellular oxidants. As a result, green fluorescence is emitted in response to ROS production and analyzed by flow cytometry. DCFH-DA (Sigma-Aldrich) was resuspended in dimethyl sulfoxide (DMSO, Sigma Aldrich). Briefly, cells were incubated with DCFH-DA solution at a final concentration of $6 \mu \mathrm{M}$ in DMEM without serum for $30 \mathrm{~min}$ at $37{ }^{\circ} \mathrm{C}$ in $5 \% \mathrm{CO}_{2}$ atmosphere. Afterward, cells were rinsed twice with PBS, collected with trypsin-EDTA solution, centrifuged at $800 \mathrm{~g}$ for $7 \mathrm{~min}$, and the supernatant was discarded. The pellets were suspended with PBS, and $1 \times 10^{4}$ events were registered for each sample by using the FACScalibur flow cytometer. ROS level was expressed as the ratio mean intensity of sample/mean intensity of control cells. The data were analyzed by WinMDI 2.8 software.

Statistical Analysis. The results are shown as mean \pm standard deviation (SD) as derived by unpaired $t$ test. The values are considered significantly different when $p<0.05$.

Conflict of Interest: The authors declare no competing financial interest.

Acknowledgment. We thank Dr. S. Moreno (Department of Biology, University of Roma Tre, Rome, Italy) for TEM analysis, and Dr. L. Canuti (Department of Biology, University of Tor Vergata, Rome, Italy) for helping with the TEM sample preparation. We would also like to thank Dr. A. Mastrofrancesco (San Gallicano Dermatological Institute IRCCS, Rome, Italy) for useful discussions about ROS analysis.

\section{REFERENCES AND NOTES}

1. Han, G.; Ghosh, P.; De, M.; Rotello, V. M. Drug and Gene Delivery Using Gold Nanoparticles. NanoBiotechnology 2007, 3, 40-45.

2. Mandoli, C.; Pagliari, F.; Pagliari, S.; Forte, G.; Di Nardo, P.; Licoccia, S.; Traversa, E. Stem Cell Aligned Growth Induced by $\mathrm{CeO}_{2}$ Nanoparticles in PLGA Scaffolds with Improved Bioactivity for Regenerative Medicine. Adv. Funct. Mater. 2010, 20, 1617-1624.

3. Karakoti, A.; Singh, S.; Dowding, J. M.; Seal, S.; Self, W. T. Redox-Active Radical Scavenging Nanomaterials. Chem. Soc. Rev. 2010, 39, 4422-4432.

4. Trovarelli, A. Catalytic Properties of Ceria and $\mathrm{CeO}_{2}-$ Containing Materials. Catal. Rev. 1996, 38, 439-520.

5. Jasinski, P.; Suzuki, T.; Anderson, H. U. Nanocrystalline Undoped Ceria Oxygen Sensor. Sens. Actuators, B 2003, 95, 73-77.

6. El-Toni, A. M.; Yin, S.; Sato, T. Enhancement of Calcia Doped Ceria Nanoparticles Performance as UV Shielding Material. Adv. Sci. Technol. 2006, 45, 673-678.

7. Esposito, V.; Traversa, E. Design of Electroceramics for Solid Oxide Fuel Cell Applications: Playing with Ceria. J. Am. Ceram. Soc. 2008, 91, 1037-1051.

8. Hailstone, R. K.; DiFrancesco, A. G.; Leong, J. G.; Allston, T. D.; Reed, K. J. A Study of Lattice Expansion in $\mathrm{CeO}_{2}$ Nanoparticles by Transmission Electron Microscopy. J. Phys. Chem. C 2009, 113, 15155-15159.

9. Zhang, F.; Wang, P.; Koberstein, J.; Khalid, S.; Chan, S. W. Cerium Oxidation State in Ceria Nanoparticles Studied with X-ray Photoelectron Spectroscopy and Absorption Near Edge Spectroscopy. Surf. Sci. 2004, 563, 74-82.

10. Migani, A; Vayssilov, G. N.; Bromley, S. T.; Illas, F.; Neyman, K. M. Greatly Facilitated Oxygen Vacancy Formation in Ceria Nanocrystallites. Chem. Commun. 2010, 46, 5936-5938.

11. Esch, F.; Fabris, S.; Zhou, L.; Montini, T.; Africh, C.; Fornasiero, P.; Comelli, G.; Rosei, R. Electron Localization Determines Defect Formation on Ceria Substrates. Science 2005, 309, 752-755.

12. Campbell, T. C.; Peden, C. H. Oxygen Vacancies and Catalysis on Ceria Surfaces. Science 2005, 309, 713-714.

13. Chen, J.; Patil, S.; Seal, S.; McGinnis, J. F. Rare Earth Nanoparticles Prevent Retinal Degeneration Induced by Intracellular Peroxides. Nat. Nanotechnol. 2006, 1, 142-150.

14. Tarnuzzer, R. W.; Colon, J.; Patil, S.; Seal, S. Vacancy Engineered Ceria Nanostructures for Protection from Radiation-Induced Cellular Damage. Nano Lett. 2005, 5, 2573-2577.

15. Das, M.; Patil, S.; Bhargava, N.; Kang, J. F.; Riedel, L. M.; Seal, S.; Hickman, J. J. Auto-catalytic Ceria Nanoparticles Offer Neuroprotection to Adult Rat Spinal Cord Neurons. Biomaterials 2007, 28, 1918-1925.

16. Fronzi, M.; Piccinin, S.; Delley, B.; Traversa, E.; Stampfl, C. Water Adsorption on the Stoichiometric and Reduced $\mathrm{CeO}_{2}(111)$ Surface: A First-Principles Investigation. Phys. Chem. Chem. Phys. 2009, 11, 9188-9199.

17. Kohen, R.; Nyska, A. Oxidation of Biological Systems: Oxidative Stress Phenomena, Antioxidants, Redox Reactions, and Methods for Their Quantification. Toxicol. Pathol. 2002, 30, 620-650.

18. Kumar, B.; Koul, S.; Khandrika, L.; Meacham, R. B.; Koul, H. K. Oxidative Stress Is Inherent in Prostate Cancer Cells and Is Required for Aggressive Phenotype. Cancer Res. 2008, 68, 1777-1785.

19. Emerit, J.; Edeas, M.; Bricaire, F. Neurodegenerative Diseases and Oxidative Stress. Biomed. Pharmacother. 2004, 58, 39-46.

20. Misra, M. K.; Sarwat, M.; Bhakuni, P.; Tuteja, R.; Tuteja, N. Oxidative Stress and Ischemic Myocardial Syndromes. Med. Sci. Monit. 2009, 15, 209-219. 
21. Finkel, T.; Holbrook, N. J. Oxidants, Oxidative Stress and the Biology of Ageing. Nature 2000, 408, 239-247.

22. Sauer, H.; Wartenberg, M.; Hescheler, J. Reactive Oxygen Species as Intracellular Messengers during Cell Growth and Differentiation. Cell. Physiol. Biochem. 2001, 11, 173-186.

23. Korsvik, C.; Patil, S.; Seal, S.; Self, W. T. Superoxide Dismutase Mimetic Properties Exhibited by Vacancy Engineered Ceria Nanoparticles. Chem. Commun. 2007, 14, 1056-1058.

24. Heckert, E. G.; Karakoti, A. S.; Seal, S.; Self, W. T. The Role of Cerium Redox State in the SOD Mimetic Activity of Nanoceria. Biomaterials 2008, 29, 2705-2709.

25. Pirmohamed, T.; Dowding, J. M.; Singh, S.; Wasserman, B.; Heckert, E.; Karakoti, A. S.; King, J. E.; Seal, S.; Self, W. T. Nanoceria Exhibit Redox State-Dependent Catalase Mimetic Activity. Chem. Commun. 2010, 46, 2736-2738.

26. Celardo, I.; De Nicola, M.; Mandoli, C.; Pedersen, J. Z.; Traversa, E.; Ghibelli, L. Ce $\mathrm{Ce}^{3+}$ lons Determine RedoxDependent Anti-apoptotic Effect of Cerium Oxide Nanoparticles. ACS Nano 2011, 5, 4537-4549.

27. Beltrami, A. P.; Cesselli, D.; Bergamin, N.; Marcon, P.; Rigo, S.; Puppato, E.; D'Aurizio, F.; Verardo, R.; Piazza, S.; Pignatelli, A.; et al. Multipotent Cells Can Be Generated in Vitro from Several Adult Human Organs (Heart, Liver, and Bone Marrow). Blood 2007, 110, 3438-3446.

28. Urbanek, K.; Torella, D.; Sheikh, F.; De Angelis, A.; Nurzynska, D.; Silvestri, F.; Beltrami, C. A.; Bussani, R.; Beltrami, A. P.; Quaini, F.; et al. Myocardial Regeneration by Activation of Multipotent Cardiac Stem Cells in Ischemic Heart Failure. Proc. Natl. Acad. Sci. U.S.A. 2005, 102, 8692-8697.

29. Bergmann, O.; Bhardwaj, R. D.; Bernard, S.; Zdunek, S.; Barnabé-Heider, F.; Walsh, S.; Zupicich, J.; Alkass, K.; Buchholz, B. A.; Druid, H.; et al. Evidence for Cardiomyocyte Renewal in Humans. Science 2009, 324, 98-102.

30. Davis, D. R.; Kizana, E.; Terrovitis, J.; Barth, A. S.; Zhang, Y.; Smith, R. R.; Miake, J.; Marbán, E. Isolation and Expansion of Functionally-Competent Cardiac Progenitor Cells Directly from Heart Biopsies. J. Mol. Cell. Cardiol. 2010, 49, 312-321.

31. Forte, G.; Carotenuto, F.; Pagliari, F.; Pagliari, S.; Cossa, P.; Fiaccavento, R.; Ahluwalia, A.; Vozzi, G.; Vinci, B.; Serafino, A.; et al. Criticality of the Biological and Physical Stimuli Array Inducing Resident Cardiac Stem Cell Determination. Stem Cells 2008, 26, 2093-2013.

32. Pagliari, S.; Vilela-Silva, A. C.; Forte, G.; Pagliari, F.; Mandoli, C.; Vozzi, G.; Pietronave, S.; Prat, M.; Licoccia, S.; Ahluwalia, A.; et al. Cooperation of Biological and Mechanical Signals in Cardiac Progenitor Cell Differentiation. Adv. Mater. 2011, 23, 514-518.

33. Matés, J. M. Effects of Antioxidant Enzymes in the Molecular Control of Reactive Oxygen Species Toxicology. Toxicology 2000, 153, 83-104.

34. Matsuura, K.; Nagai, T.; Nishigaki, N.; Oyama, T.; Nishi, J.; Wada, H.; Sano, M.; Toko, H.; Akazawa, H.; Sato, T.; et al. Adult Cardiac Sca-1-Positive Cells Differentiate into Beating Cardiomyocytes. J. Biol. Chem. 2003, 279, 11384-11391.

35. Tateishi, K; Ashihara, E.; Takehara, N.; Nomura, T.; Honsho, S.; Nakagami, T.; Morikawa, S.; Takahashi, T.; Ueyama, T.; Matsubara, H.; et al. Clonally Amplified Cardiac Stem Cells Are Regulated by Sca-1 Signaling for Efficient Cardiovascular Regeneration. J. Cell. Sci. 2007, 15, 1791-1800.

36. Brunner, T. J.; Wick, P.; Manser, P.; Spohn, P.; Grass, R. N.; Limbach, L. K.; Bruinink, A.; Stark, W. J. In Vitro Cytotoxicity of Oxide Nanoparticles: Comparison to Asbestos, Silica, and the Effect of Particle Solubility. Environ. Sci. Technol. 2006, 40, 4374-4381.

37. Gojova, A.; Guo, B.; Kota, R. S.; Rutledge, J. C.; Kennedy, I. M.; Barakat, A. I. Induction of Inflammation in Vascular Endothelial Cells by Metal Oxide Nanoparticles: Effect of Particle Composition. Environ. Health Perspect. 2007, 115, 403-409.

38. Jawad, H.; Boccaccini, A. R.; Ali, N. N.; Harding, S. Assessment of Cellular Toxicity of $\mathrm{TiO}_{2}$ Nanoparticles for Cardiac Tissue Engineering Applications. Nanotoxicology 2011, 5, 372-380.

39. Moghimi, S. M.; Peer, D.; Langer, R. Reshaping the Future of Nanopharmaceuticals: Ad ludicium. ACS Nano 2011, 5 , 8454-8458.
40. Au, K. W.; Liao, S. Y.; Lee, Y. K.; Lai, W. H.; Ng, K. M.; Chan, Y. C.; Yip, M. C.; Ho, C. Y.; Wu, E. X.; Li, R. A.; et al. Effects of Iron Oxide Nanoparticles on Cardiac Differentiation of Embryonic Stem Cells. Biochem. Biophys. Res. Commun. 2009, 379, 898-903.

41. Hess, H.; Tseng, Y. Active Intracellular Transport of Nanoparticles: Opportunity or Threat?. ACS Nano 2007, 1, 390392.

42. Kocbek, P.; Teskac, K.; Kreft, M. E.; Kristl, J. Toxicological Aspects of Long-Term Treatment of Keratinocytes with ZnO and $\mathrm{TiO}_{2}$ Nanoparticles. Small 2010, 6, 1908-1917.

43. Dobrovolskaia, M. A.; McNeil, S. E. Immunological Properties of Engineered Nanomaterials. Nat. Nanotechnol. 2007, 2, 469-478.

44. Celardo, I.; Pedersen, J. Z.; Traversa, E.; Ghibelli, L. Pharmacological Potential of Cerium Oxide Nanoparticles. Nanoscale 2011, 3, 1411-1420.

45. Forte, G.; Pietronave, S.; Nardone, G.; Zamperone, A.; Magnani, E.; Pagliari, S.; Pagliari, F.; Giacinti, C.; Nicoletti, C.; Musarò, A.; et al. Human Cardiac Progenitor Cell Grafts as Unrestricted Source of Supernumerary Cardiac Cells in Healthy Murine Hearts. Stem Cells 2011, 29, 2051-2061.

46. Di Nardo, P.; Forte, G.; Ahluwalia, A.; Minieri, M. Cardiac Progenitor Cells: Potency and Control. J. Cell. Physiol. 2010, 224, 590-600.

47. Park, E. J.; Choi, J.; Park, Y. K.; Park, K. Oxidative Stress Induced by Cerium Oxide Nanoparticles in Cultured BEAS-2B Cells. Toxicology 2008, 245, 90-100.

48. Gojova, A.; Lee, J. T.; Jung, H. S.; Guo, B.; Barakat, A. I.; Kennedy, I. M. Effect of Cerium Oxide Nanoparticles on Inflammation in Vascular Endothelial Cells. Inhal. Toxicol. 2009, 21, 123-130.

49. Pourkhalili, N.; Hosseini, A.; Nili-Ahmadabadi, A.; Hassani, S.; Pakzad, M.; Baeeri, M.; Mohammadirad, A.; Abdollahi, M. Biochemical and Cellular Evidence of the Benefit of Combination of Cerium Oxide Nanoparticles and Selenium to Diabetic Rats. World J. Diabetes 2011, 2, 204-210.

50. Li, T. S.; Marbán, E. Physiological Levels of Reactive Oxygen Species Are Required To Maintain Genomic Stability in Stem Cells. Stem Cells 2010, 28, 1178-1185.

51. Karakoti, A.; Tsigkou, O.; Yue, S.; Lee, P. D.; Stevens, M. M.; Jones, J. R.; Seal, S. Rare Earth Oxides as Nanoadditives in 3-D Nanocomposite Scaffolds for Bone Regeneration. J. Mater. Chem. 2010, 20, 8912-8919.

52. Hirst, S. M.; Karakoti, A. S.; Tyler, R. D.; Sriranganathan, N.; Seal, S.; Reilly, C. M. Anti-inflammatory Properties of Cerium Oxide Nanoparticles. Small 2009, 5, 2848-2856.

53. Lynch, I.; Salvati, A.; Dawson, K. A. Protein-Nanoparticle Interactions: What Does the Cell See?. Nat. Nanotechnol. 2009, 4, 546-547.

54. Patil, S.; Sandberg, A.; Heckert, E.; Self, W.; Seal, S. Protein Adsorption and Cellular Uptake of Cerium Oxide Nanoparticles as a Function of Zeta Potential. Biomaterials 2007, 28, 4600-4607.

55. Limbach, L. K.; Li, Y.; Grass, R. N.; Brunner, T. J.; Hintermann, M. A.; Muller, M.; Gunther, D.; Stark, W. J. Oxide Nanoparticle Uptake in Human Lung Fibroblasts: Effects of Particle Size, Agglomeration, and Diffusion at Low Concentrations. Environ. Sci. Technol. 2005, 39, 9370-9376.

56. Morikawa, S.; Mabuchi, Y.; Kubota, Y.; Nagai, Y.; Niibe, K.; Hiratsu, E.; Suzuki, S.; Miyauchi-Hara, C.; Nagoshi, N.; Sunabori, T.; et al. Prospective Identification, Isolation, and Systemic Transplantation of Multipotent Mesenchymal Stem Cells in Murine Bone Marrow. J. Exp. Med. 2009, 206, 2483-2496.

57. Frank, O.; Heim, M.; Jakob, M.; Barbero, A.; Schäfer, D.; Bendik, I.; Dick, W.; Heberer, M.; Martin, I. Real-Time Quantitative RT-PCR Analysis of Human Bone Marrow Stromal Cells during Osteogenic Differentiation in Vitro. J. Cell. Biochem. 2002, 85, 737-746.

58. Eruslanov, E.; Kusmartsev, S. Identification of ROS Using Oxidized DCFDA and Flow-Cytometry. Methods Mol. Biol. 2010, 594, 57-72. 